\title{
Comparing the effect of a swirl flap and asymmetric inlet valve opening on a light duty diesel engine
}

\author{
Felix Leach, Martin Davy \\ University of Oxford
}

\author{
Adam Weall, Brian Cooper \\ Jaguar Land Rover Ltd
}

Copyright $\odot 2017$ SAE International

\begin{abstract}
Diesel engine designers often use swirl flaps to increase air motion in cylinder at low engine speeds, where lower piston velocities reduce natural in-cylinder swirl. Such in-cylinder motion reduces smoke and $\mathrm{CO}$ emissions by improved fuel-air mixing. However, swirl flaps, acting like a throttle on a gasoline engine, create an additional pressure drop in the inlet manifold and thereby increase pumping work and fuel consumption. In addition, by increasing the fuel-air mixing in cylinder the combustion duration is shortened and the combustion temperature is increased; this has the effect of increasing $\mathrm{NO}_{\mathrm{x}}$ emissions. Typically, EGR rates are correspondingly increased to mitigate this effect. Late inlet valve closure, which reduces an engine's effective compression ratio, has been shown to provide an alternative method of reducing $\mathrm{NO}_{\mathrm{x}}$ emissions. Recently introduced technologies combine these two effects by retarding only the swirl port valve, increasing in-cylinder swirl while simultaneously reducing the effective compression ratio.
\end{abstract}

In this paper the effects of using a swirl flap and offset cams are compared. Four different swirl flap positions (ranging from fully open to fully closed) were investigated using standard cams and valve timings. Results were compared with the engine's operation when using two offset cams providing two different levels of retard on the swirl port -30 and 60 crank angle degrees (CAD) respectively. Engine emissions, fuel consumption, and combustion parameters were measured and compared in order to elucidate the effects of phased cam operation.

The results show that the use of a cam retarding the opening of the swirl port can reduce $\mathrm{NO}_{\mathrm{x}}$ emissions at certain speed/load conditions without adversely affecting other emissions. In addition significantly retarding the swirl port closure can reduce FSN emissions to near zero with low $\mathrm{NO}_{\mathrm{x}}$ emissions, by a combination of high levels of swirl and a reduced effective compression ratio.

\section{Introduction}

Diesel powered cars can emit up to $20 \%$ less $\mathrm{CO}_{2}$ than their gasoline counterparts [1]. In 2015 the number of vehicles emitting below 95 $\mathrm{g} / \mathrm{km} \mathrm{CO}_{2}$ sold in the UK was around 240,000 of which $24 \%$ were alternatively fuelled vehicles (i.e. not petrol or diesel), $26 \%$ petrol and $50 \%$ diesel [1]. Clearly, a reduction in sales of new diesel vehicles would severely impact the ability to meet legislated fleet $\mathrm{CO}_{2}$ targets, at least in the short term. However it is known that diesel engines can emit more $\mathrm{NO}_{\mathrm{x}}$, soot, and other pollutants without aftertreatment (which is of course present on all modern production engines to limit these pollutants) [2]. Techniques to reduce pollutants emitted during diesel combustion are therefore of interest in order to reduce the burden on the aftertreatment system.

During combustion in a diesel engine, in cylinder motion, and swirl specifically, promote turbulence which aids the transfer of oxygen into local reaction zones [3]. Swirl is usually referred to as motion around the cylinder axis, with tumble the motion orthogonal to that. As the piston approaches top dead centre (tdc) the tumble tends to break down, and the swirl is left as the main contributor to turbulence after this point. Given the importance of fuel-air mixing in compression ignition engines a good understanding of the in cylinder air motion, and swirl in particular, is important across the engine operating map.

At high engine speeds combustion chamber and inlet design gives sufficient swirl to mix fuel and air, due to the faster piston speeds, and correspondingly higher inlet air velocities. However at low speed swirl levels can fall, and if additional swirl is required (to obtain enough fuel-air mixing for emissions control for example) another technique must be employed to generate the extra swirl. Zuelch et al. have described the areas of a diesel engine operating map that most benefit from swirl [4]. Herzog [5] reported that by deactivating one inlet valve in a 1998 engine the $\mathrm{NO}_{\mathrm{x}}$-soot tradeoff was significantly improved at low engine speed and light load due to the increase in swirl. Herzog also reported that there was still an improvement at higher loads whilst still at low engine speeds. 
Swirl flaps have been used to control in cylinder air motion and generate extra swirl at low engine speeds and loads. The BMW's M47 4 cylinder diesel engines featured a swirl flap from 2001 and Audi launched their 4.0 L V8 diesel engine featuring a swirl flap in $2003[6,7]$. Activating a swirl flap (SF) will have a similar effect to a throttle on a gasoline engine in reducing the amount of air that flows into the cylinder (although of course the effect will be less than on a gasoline engine as the "throttle" is only in one inlet port) which would be undesirable at high engine speeds (when the swirl is higher anyway) so swirl flaps tend only to be used for emissions control at low speed, light load conditions [8].

Late inlet valve closure (LIVC) is a technique that has been explored to reduce fuel consumption by reducing pumping work in diesel engines. Lancefield [9] reported that in a $2 \mathrm{~L}, 4$-cylinder diesel engine light load fuel consumption could be reduced by up to $6 \%$ by retarding intake valve closure by $33 \mathrm{CAD}$ from the standard timing. Lancefield reported that this was mostly due to the reduction in mass flow of air through the engine, reducing pumping and compression work.

LIVC also acts to decrease the effective compression ratio (CR). Ogawa et al. [10] investigated the effect of reducing the CR on a single cylinder $1 \mathrm{~L}$ engine. They found that lowering the $\mathrm{CR}$ reduced smoke emissions, particularly at higher levels of EGR and attributed this reduction to the improved mixing due to increased ignition delay and a decrease in in-cylinder temperatures (due to lower compression). However, the reduction in trapped mass being compressed led to combustion that was closer to stoichiometric, and this reduced the thermal efficiency.

A combination of these effects were tested by Gurney et al. using continuously variable cam phasing on $2.0 \mathrm{~L}$ 4-cylinder engine [11].. In this work, a number of simulations were done in GT Power and engine testing was done fixing the SF open, and phasing the flow port by up to $60 \mathrm{CAD}$ at $1500 \mathrm{rpm} / 50 \mathrm{Nm}$. Gurney et al. showed that increased charge motion reduced soot while the reduced effective compression ratio reduced $\mathrm{NO}_{\mathrm{x}}$. With these reductions in emissions Gurney et al. reported no change in brake specific fuel consumption (bsfc) with phased cams, but an increase of $1.7 \%$ in bsfc with the swirl flap closed $90 \%$. More recently, the VW EA288 engine uses valve phasing of up to $50 \mathrm{CAD}$ to control emissions and reduce engine warm-up time [12].

This study aims to compare the effects of using a swirl flap to control low speed / part load emissions with using asymmetric inlet valve opening and its effect on burn rates and indicated specific fuel consumption (ISFC) on a single cylinder high-speed diesel engine representative of current market engines.

\section{Experimental methodology}

\section{Engine}

These tests were run on a single cylinder high speed diesel engine supplied by Jaguar Land Rover (JLR). The engine has a Ricardo Hydra base, and the combustion system, cylinder head, and geometry are all the same as the JLR AJ200D "Ingenium" engine [13]. A nonproduction standard bowl (described in [14]) was fitted alongside a production standard fuel injection system. Table 1 shows the engine specification. Cooled, high pressure EGR is used on this engine. The engine and test cell installation are fully described in [14].
Table 1: Specifications of the single-cylinder diesel engine

\begin{tabular}{|l|l|}
\hline Bore $\times$ Stroke & $83 \times 92.4 \mathrm{~mm}$ \\
\hline Displacement & $500 \mathrm{~cm}^{3}$ \\
\hline Valves per Cylinder & 2 intake, 2 exhaust \\
\hline Compression Ratio & $15.2: 1$ \\
\hline Fuel Pressure & $400-1800$ bar \\
\hline Injector & Production 'Ingenium' engine injector \\
\hline
\end{tabular}

There are two inlet ports fitted to the cylinder head, a tangential or directed port which is the primary swirl generator and a helical port often described as a filling port. It is the valve fitted in this latter helical port that is retarded and also this port that the swirl flap is fitted in. In this paper we refer to this helical port as the swirl port.

The swirl flap on this engine was a VDO brand throttle fitted in the swirl port approximately $15 \mathrm{~cm}$ upstream of the inlet valve. Its position was controlled by the ECU, and a demand of 0 corresponds to fully open, and 100 to fully closed.

\section{Effect of swirl flap on swirl ratio}

The cylinder head fitted to the engine has been tested for swirl at a variety of SF positions using the Ricardo method [15]. Figure 1 shows the measured swirl ratios for this swirl flap sweep, it can be seen that the swirl ratio doubles as the SF closes. The tested SF positions - open, 70, 90, and closed were determined from this graph to give a spread of swirl levels in cylinder.

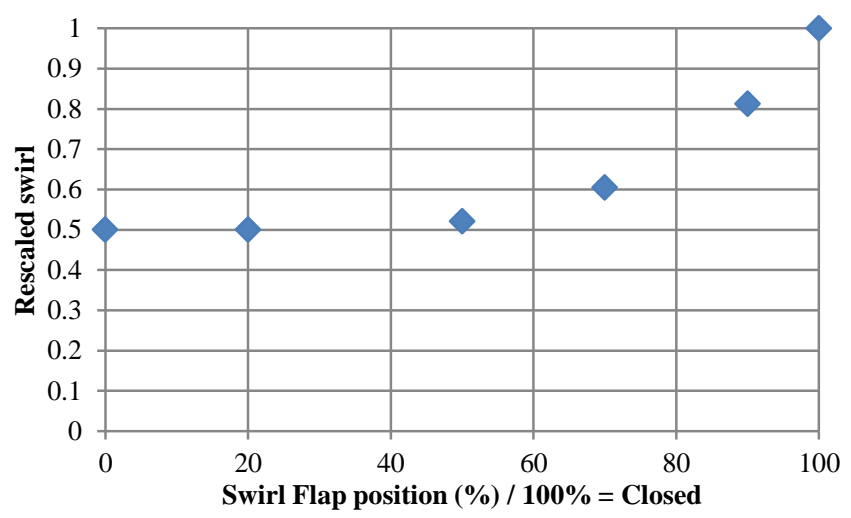

Figure 1: The measured swirl ratio as the swirl flap is closed - a doubling of in cylinder swirl can be seen with the SF fully closed.

\section{Valvetrain}

The effect of phased inlet cams was examined by running the engine with three different inlet cams - a baseline cam and two other inlet cams, one with the lobe on the swirl port retarded by $30 \mathrm{CAD}$, and the other by $60 \mathrm{CAD}$. $60 \mathrm{CAD}$ retard was chosen as it is the maximum retard available in commercial products $[11,16]$. The flow port always had the baseline timing. These cams were replaced manually in the cam carrier on the engine, this involved removing and refitting the cambelts each time they were replaced and retiming the engine - on each build a target of $\pm 0.5 \mathrm{CAD}$ from nominal was set for the cam timing, and this was achieved in every case (and 
$\pm 0.3 \mathrm{CAD}$ from nominal was achieved on the inlet cam). Figure 2 shows the valve lift profiles for the inlet and exhaust cams used in this work. The engine was not fitted with variable valve actuation on either inlet or exhaust side. The exhaust cam profile matched the profile of the cams on the Ingenium engine and was unchanged and remained at fixed timing throughout these tests.

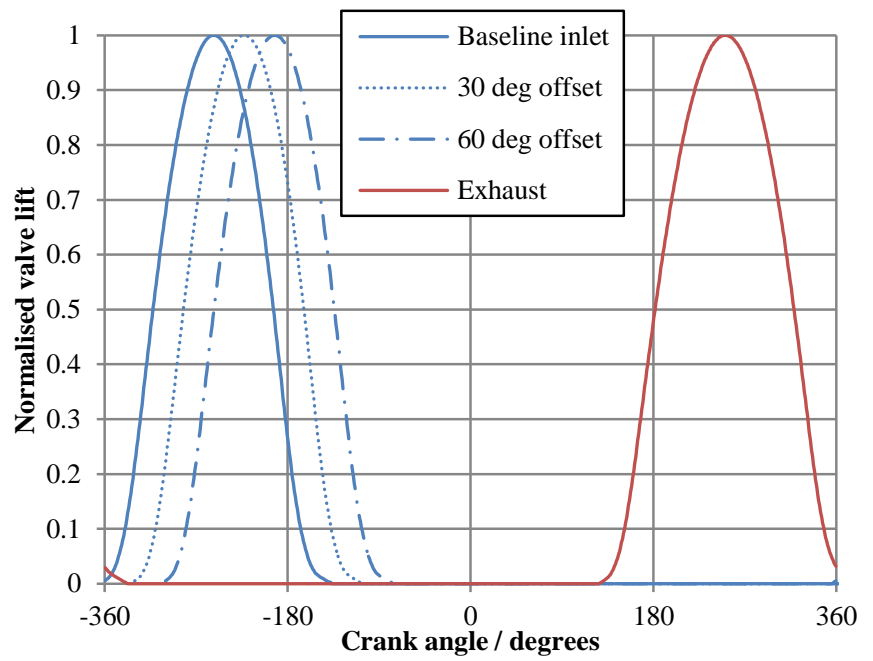

Figure 2: Inlet and exhaust cam lift profiles showing the exhaust (red, unphased) and three inlet swirl port phases tested (baseline, $30 \mathrm{CAD}$ offset, and $60 \mathrm{CAD}$ offset). The inlet flow port always had the baseline timing. $0 \mathrm{CAD}$ on the abscissa corresponds to tdc firing.

\section{Effect on compression ratio}

In phasing the swirl port, the effective CR of the engine is reduced (as IVC of one valve occurs well into the compression stroke). Figure 3 shows the calculated effective compression ratios for the three swirl port cam timings. The $60 \mathrm{CAD}$ retarded cam gives a significant reduction in effective CR from 15.2 to about 9.1 and the $30 \mathrm{CAD}$ retarded cam gave a less significant reduction in effective CR.

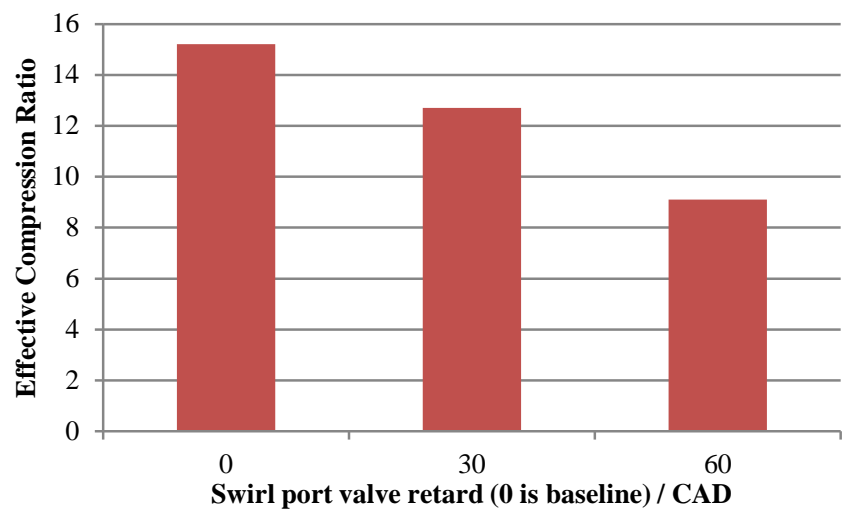

Figure 3: Calculated effective compression ratio as the swirl port opening is retarded

Page 3 of 13

\section{Effect on swirl}

Figure 4 shows simulation results from STAR-CD [17] of the effect of the retarded swirl port timing and the fully closed SF on the swirl levels in cylinder. Note here that the swirl here is calculated according to the method shown in [17] rather than the Ricardo method [15] shown in Figure 1. Comparing Figure 4 with Figure 1 it can be seen that the swirl levels from the $60 \mathrm{CAD}$ retard corresponds approximately to the SF90 position.

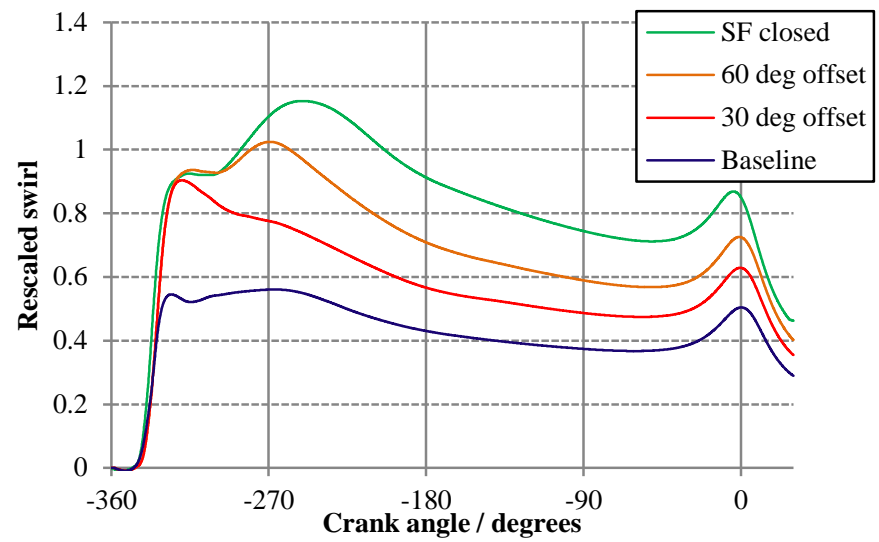

Figure 4: Predicted swirl levels with the offset swirl port cams -the $60 \mathrm{CAD}$ offset cam can be seen to give swirl levels similar to SF90 position, and the $\mathrm{SF}$ closed position gives the highest overall swirl levels. 0 CAD on the abscissa corresponds to tdc firing.

\section{Instrumentation}

The test cell instrumentation has been comprehensively described in [14]. Each of the inlet runners, upstream of the swirl and flow ports (respectively) are fitted with a Kistler 4005BA5FV200S high speed pressure transducer approximately $10 \mathrm{~cm}$ upstream of each inlet valve. These Kistlers, alongside other pressure data, and the injection current signal were logged by an AVL advanced indiset 642 at a resolution of $0.1 \mathrm{CAD}$. Other parameters were logged by Sierra-CP Cadet software at $1 \mathrm{~Hz}$. The engine is not fitted with a catalyst, and emissions were measured by an AVL415S smoke meter, and a Horiba MEXA-ONE approximately $1 \mathrm{~m}$ downstream of the exhaust backpressure valve. EGR rate is calculated using the intake and exhaust $\mathrm{CO}_{2}$ levels. The engine was controlled by a Pi Innovo M670 OpenECU.

\section{Fuel}

The tests were run using an EN590 [18] B0 standard diesel. Table 2 shows the properties of the diesel tested.

Table 2: Diesel fuel composition

\begin{tabular}{|l|l|}
\hline Cetane Number & 53.0 \\
\hline IBP $\left({ }^{\circ} \mathrm{C}\right)$ & 171.4 \\
\hline FBP $\left({ }^{\circ} \mathrm{C}\right)$ & 355.0 \\
\hline Aromatics $(\% \mathrm{~m} / \mathrm{m})$ & 25.1 \\
\hline Sulfur $(\mathrm{mg} / \mathrm{kg})$ & 6.5 \\
\hline
\end{tabular}




\begin{tabular}{|l|l|}
\hline FAME (\% v/v) & $<0.1$ \\
\hline
\end{tabular}

\section{Results and Discussion}

The engine was run at two fixed speed/load operating points as shown in Table 3. The EGR rate was varied in five equal steps at a constant exhaust backpressure and inlet manifold pressure - the maximum EGR rate was dictated by an upper value in smoke emissions (FSN) or a breakdown in combustion stability, which varied with SF position and cam - a more detailed discussion of this is presented below. The CA50 (angle of $50 \%$ mass fraction burned) was held constant for each test point, with a small pilot of fixed quantity used, at a fixed CAD separation from the main injection. The engine load was set by varying the main injection quantity to match the desired net IMEP (nIMEP), which was held constant through the EGR sweep. The variation in nIMEP was $<0.7 \%$, and a number of repeats were carried out to give confidence in the measurements. Three inlet cams were tested baseline, $30 \mathrm{CAD}$ offset and $60 \mathrm{CAD}$ offset, and four SF positions baseline (open), SF70, SF90 (corresponding to $70 \%$ and $90 \%$ closed respectively), and SF closed - all with the baseline cam.

Table 3: Engine operating points

\begin{tabular}{|c|c|c|c|}
\hline Test point ID & $1500 / 3.5$ & $1500 / 6.8$ & 1750/13.5 \\
\hline Engine speed (rpm) & 1500 & 1500 & 1750 \\
\hline nIMEP (bar) & 3.5 & 6.8 & 13.5 \\
\hline Inlet manifold pressure (barG) & 0.03 & 0.25 & 1.0 \\
\hline Exhaust backpressure (barG) & 0.15 & 0.45 & 1.4 \\
\hline Inlet air temperature $\left({ }^{\circ} \mathrm{C}\right)$ & \multicolumn{3}{|c|}{ Varies with EGR } \\
\hline Coolant and oil temperature $\left({ }^{\circ} \mathrm{C}\right)$ & \multicolumn{3}{|c|}{90} \\
\hline EGR range (approx.)* & $0-50 \%$ & $0-45 \%$ & $0-25 \%$ \\
\hline CA50 (CAD) & 13.6 & 9.5 & 11.4 \\
\hline Fuel rail pressure (MPa) & 40 & 55 & 90 \\
\hline
\end{tabular}

*EGR set points varied depending on whether swirl flap or offset cam was used as detailed in the discussion.

Data was collected at each test point over a three minute period, and mean values were calculated. All emissions readings have been rescaled by dividing by a nominal value - the same nominal value for all load points. All of the data is presented against $\mathrm{ISNO}_{\mathrm{x}}$, as the effect of the asymmetric cam profile on $\mathrm{ISNO}_{\mathrm{x}}$ is of the highest interest.

Figure 5 and Figure 6 show the pressure in each of the inlet ports at 1500/6.8. The effect of the swirl flap can clearly be seen in Figure 5, with the pressure in the swirl port dropping by 0.15 bar relative to the flow port and baseline swirl port case as the inlet valves open with the SF closed - this will result in increased pumping work, and less air entering the cylinder. The SF70 and SF90 cases show intermediate effects. The pressure in the flow port remains independent of SF position. Figure 7 shows a detailed view of Figure 6 showing clearly the effect of the retarded swirl port opening, with the overall pressure magnitudes remaining constant between the swirl and flow ports, however the retarded port is offset by the angle of retardation, there is no pressure drop such as seen in Figure 5. The other test points show identical port pressure trends to $1500 / 6.8$ just at different overall magnitudes.

Page 4 of 13

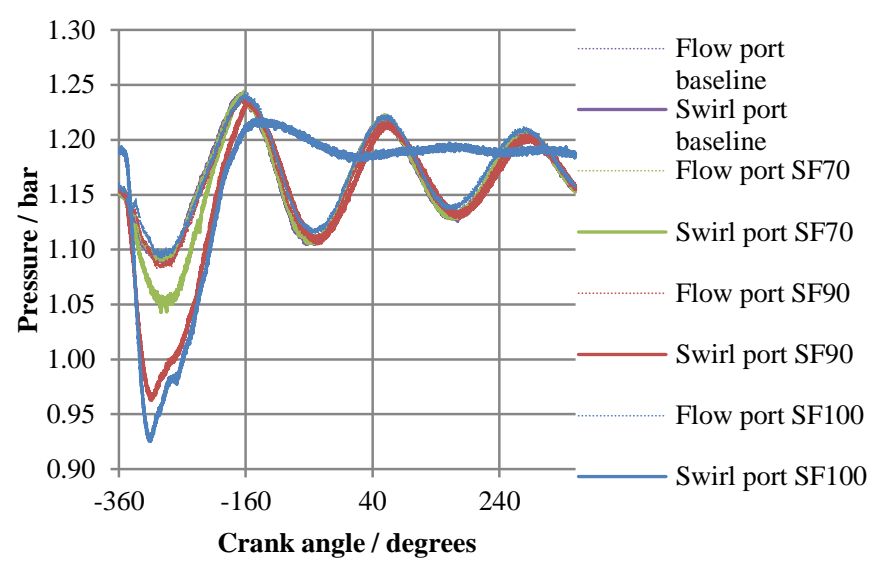

Figure 5: Inlet flow and swirl port pressures at 1500/6.8 as the Swirl Flap is operated - IVO baseline is - $360 \mathrm{CAD}$

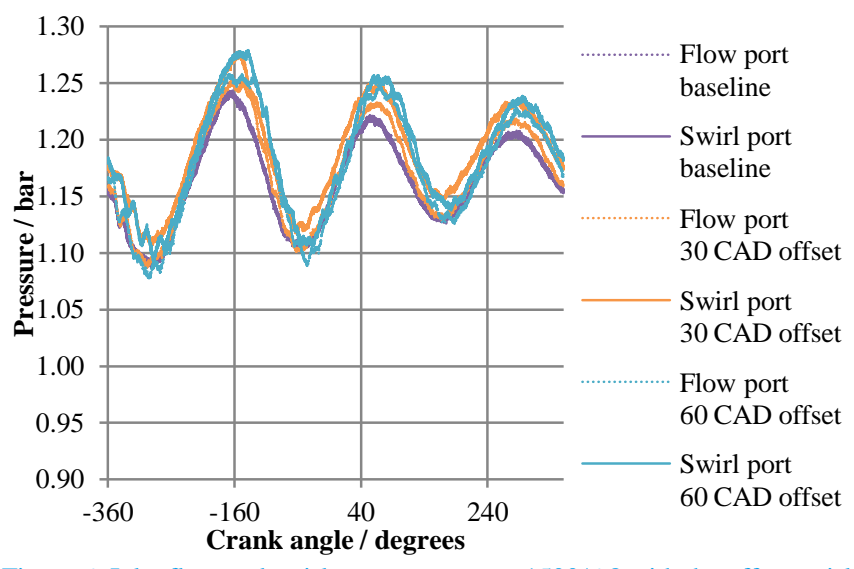

Figure 6: Inlet flow and swirl port pressures at 1500/6.8 with the offset swirl port cams - IVO baseline is - 360 CAD

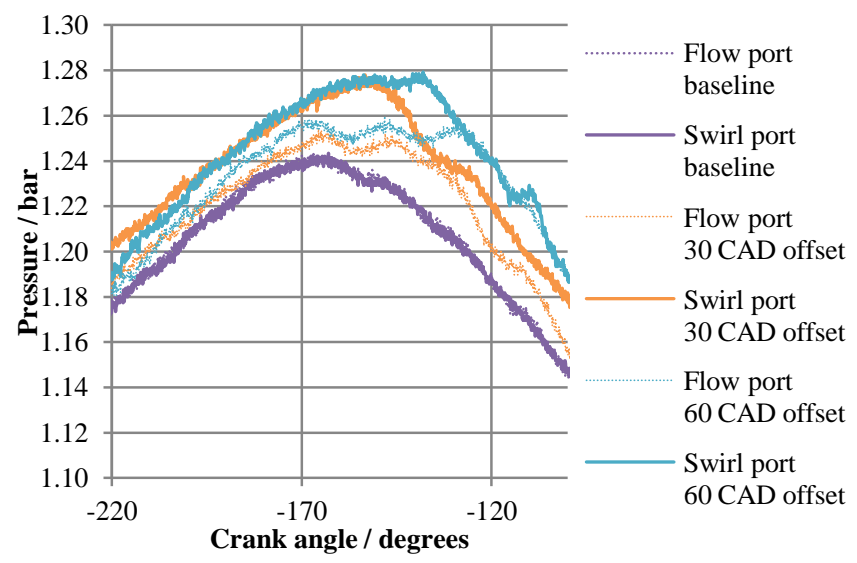

Figure 7: Rescaled Figure 6 showing inlet flow and swirl port pressures at $1500 / 6.8$ with the offset swirl port cams - IVO baseline is - 360 CAD

The effect of these pressure drops on Pumping Mean Effective Pressure (PMEP) can be seen in Figure 8. The SF closed case gives 
the highest pumping work, about a $17 \%$ increase compared to the baseline case. As would be expected comparing Figure 5 with Figure 8, the PMEPs for the SF70 and baseline case are essentially the same and the two offset cams show PMEPs to be in line with the SF90 case. This is likely due to the pumping losses associated with backflow through the retarded swirl port inlet valve during the compression stroke. This can be seen in Figure 6 with the small increase in pressure seen around -160 CAD, when compression has started, but the swirl port inlet valve is still open. Although Figure 8 only shows the PMEP at 1750/13.5, the trends for PMEP at all three load conditions are the same, and omitted here for brevity.

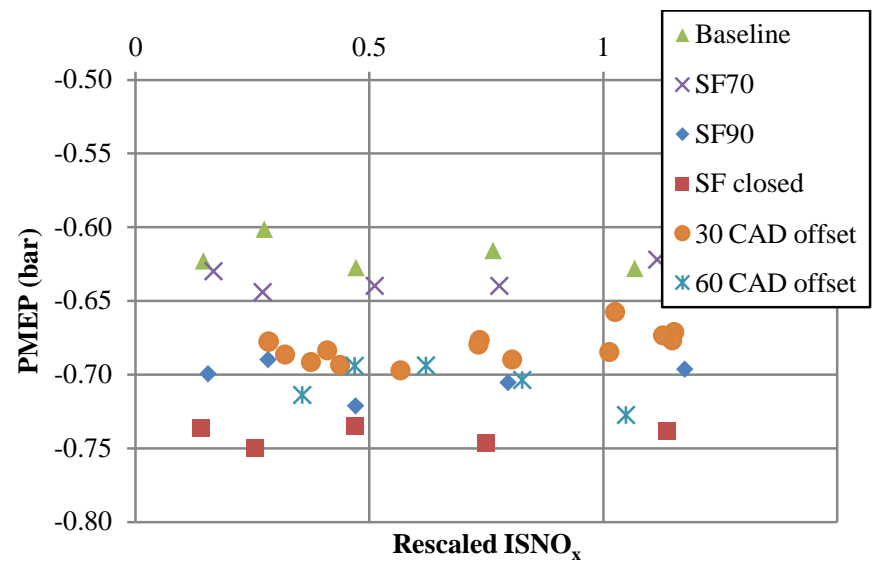

Figure 8: The Pumping Mean Effective Pressure (PMEP) at 1750/13.5 for the SF sweep and offset cam cases. Clearly, closing the SF fully results in the highest pumping work, with the offset cams showing pumping work approximately the same as the SF90 case.

The effect that the SF and offset cams have on lambda is shown in Figure 9. The offset cams can be seen significantly to reduce lambda, particularly at lower levels of EGR (higher levels of $\mathrm{ISNO}_{\mathrm{x}}$ ) showing the effect of the reduced effective $\mathrm{CR}$ on oxygen availability in cylinder. Closing the SF also reduced oxygen availability - and hence lambda due to the pressure drop introduced in the swirl port by the SF. The other engine operating points showed equivalent effects.

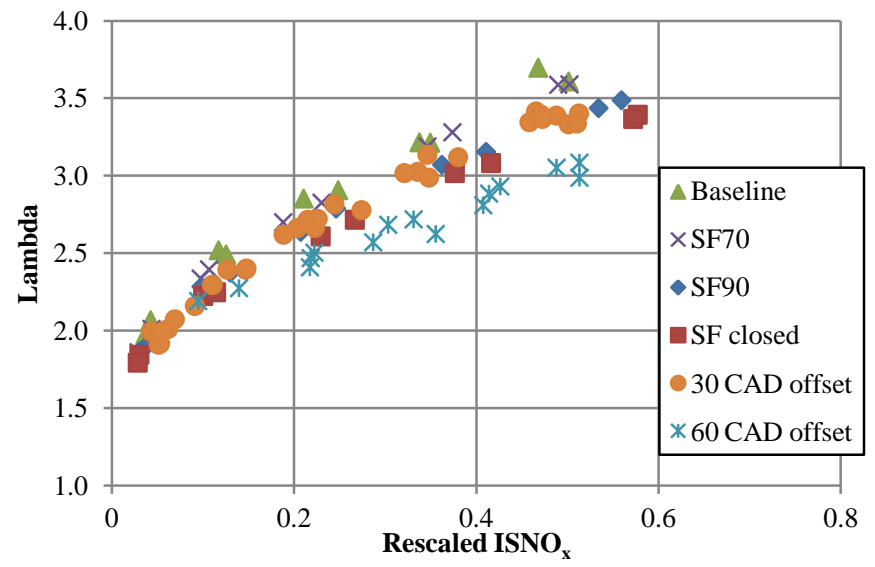

Figure 9: Lambda at 1500/3.5. The effect of the offset cams and SF activation in reducing oxygen availability can clearly be seen.

\section{$1500 \mathrm{rpm} / 3.5$ bar nIMEP}

Figure 10 shows the FSN emissions at 1500/3.5. The Baseline and SF70 cases show the traditional $\mathrm{NO}_{\mathrm{x}}-$ Soot tradeoff with higher levels of EGR decreasing the $\mathrm{ISNO}_{\mathrm{x}}$ emitted, and increasing the FSN. However the SF90, SF closed and two offset cams show a reduction of FSN with increasing EGR. This is clearly suggests that the engine is operating in a Low Temperature Combustion (LTC) regime [19] under these conditions - note that Figure 17 later shows that the EGR rates at the lowest $\mathrm{ISNO}_{\mathrm{x}}$ points are $\sim 50 \%$. The $30 \mathrm{CAD}$ offset cam gives a virtually identical $\mathrm{NO}_{\mathrm{x}}$-soot trend to the $\mathrm{SF} 90$ case, and the $60 \mathrm{CAD}$ offset cam gives the greatest benefit of all, with virtually smokeless combustion across the EGR range, improving with increasing EGR. There is clearly excellent fuel-air mixing in the lowest FSN cases, causing very low soot formation due to very high levels of swirl.

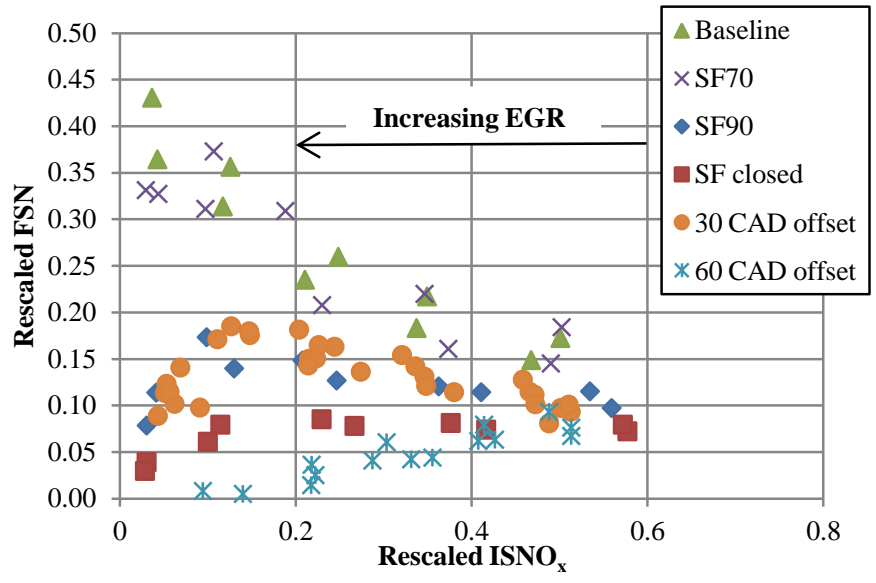

Figure 10: FSN emissions at 1500/3.5. The 60 CAD offset cam emits virtually no soot at high levels of EGR (low ISNO ${ }_{x}$ levels).

Figure 11 and Figure 12 show the ISTHC and ISCO emissions (respectively) at 1500/3.5. With both emissions, the baseline, SF70, and SF90 cases give low emissions, with a small increase at high levels of EGR (low ISNO ${ }_{x}$ ), which follows what has been seen in the literature [20] and which is attributed to the incomplete combustion of poorly mixed fuel/charge mixtures. The SF closed and $30 \mathrm{CAD}$ offset cam cases show slightly higher levels of ISCO and ISTHC than the baseline whereas the 60 CAD offset cam shows significantly increased emissions of both pollutants. It is likely that this increase is caused by overly high levels of swirl at this condition convecting heat away from combustion before it has time to complete, combined with reduced oxygen availability - due to the significantly decreased compression ratio (see Figure 3). 


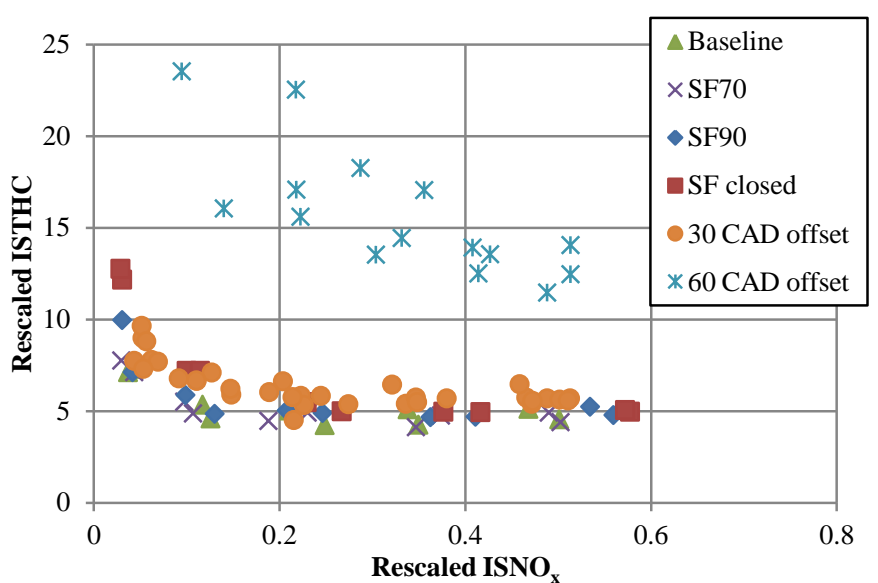

Figure 11: ISTHC emissions at 1500/3.5. The baseline gives the lowest ISTHC emissions, with a small increase for the $30 \mathrm{CAD}$ offset cam and SF closed case. The $60 \mathrm{CAD}$ offset cam gives the highest ISTHC emissions.

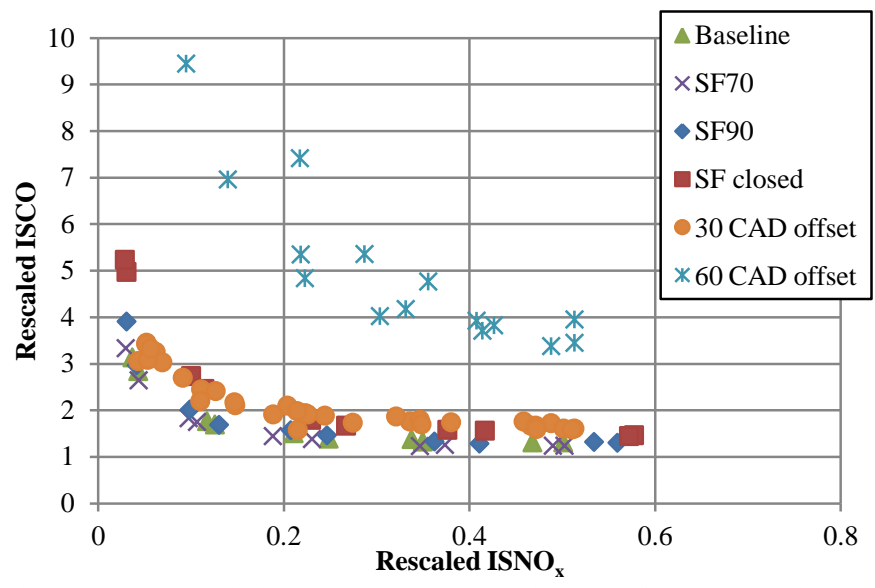

Figure 12: ISCO emissions at 1500/3.5. Small increases from the baseline are seen for the $30 \mathrm{CAD}$ offset cam, and the SF closed case. The $60 \mathrm{CAD}$ offset cam gives the highest ISCO emissions.

Figure 13 shows the ISFC at 1500/3.5. The effect of the increased pumping work on the ISFC as the swirl flap is closed (Figure 8) can clearly be seen as there is a monotonic increase in ISFC with closing swirl flap - an increase of around $6 \%$. The 30 CAD offset case, follows this trend too, with its ISFC matching the SF90 case, in line with their matching PMEPs. However the $60 \mathrm{CAD}$ offset cam case shows a marked increase in ISFC (an increase of 8-10\% on the baseline). This can be attributed (in part) to the increase in PMEP and in part to the significant increase in THC emissions - effectively unburned fuel. It might be expected that the effective increase in the expansion stroke relative to the inlet stroke caused by the late inlet valve closure might lead to a reduction in fuel consumption, due to the Atkinson cycle like operation [21], however, it seems that the very high swirl levels causing incomplete combustion, and hence unburned fuel, are masking any effect this might have, as it is not observed in our results.

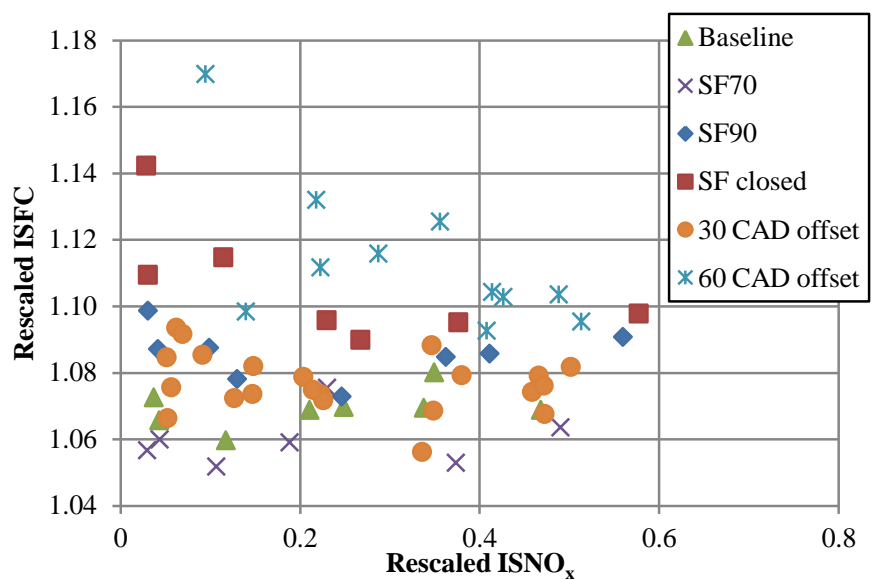

Figure 13: ISFC results at 1500/3.5. Closing the SF gives and increase in ISFC, a minor increase from baseline is noted for the $30 \mathrm{CAD}$ offset cam and a more significant increase for the $60 \mathrm{CAD}$ offset cam.

Figure 14 shows the CA10-MSOI values - a measure of the ignition delay at 1500/3.5. The well documented effect of adding EGR increasing the ignition delay due to decreased oxygen availability is clearly seen [22]. Closing the SF can be seen to increase the ignition delay, in line with what has been reported in the literature [11], this is due to the increased swirl leading to more heat being convected away from the combustion process in the initial stages. The $60 \mathrm{CAD}$ offset cam shows the highest ignition delay (by a significant margin) this is due to a combination of the high levels of swirl, and the reduced in cylinder temperatures and pressures at injection. In addition, because of the reduced effective CR, the amount of oxygen present is also reduced. All of these effects combine to increase the ignition delay with this cam significantly.

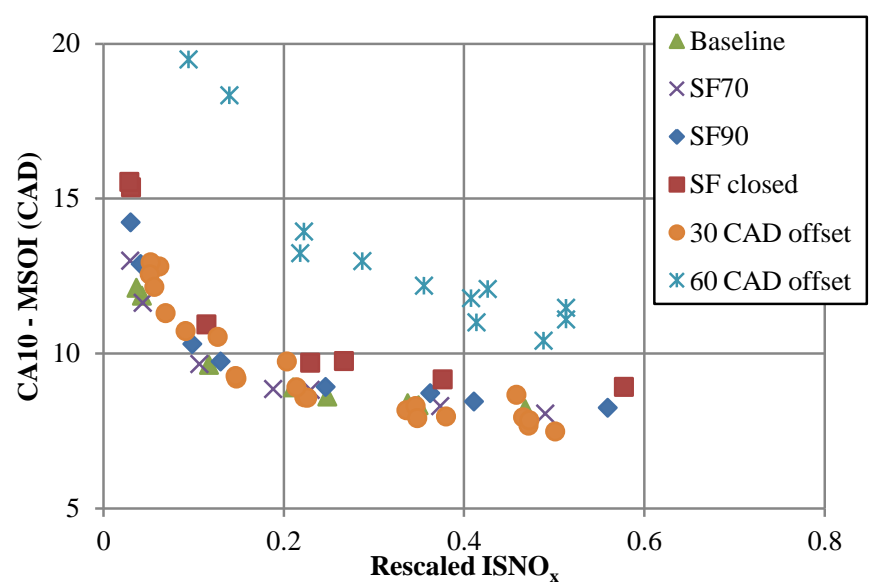

Figure 14: Ignition delay at 1500/3.5. The 60 CAD offset cam can be seen to give the longest ignition delay due to the increased swirl, reduced in cylinder temperature and pressure, and reduced oxygen availability.

Figure 15 and Figure 16 show the $10-50 \%$ and $50-90 \%$ mass fraction burned durations respectively. The SF closed and $60 \mathrm{CAD}$ offset cam show the fastest initial burn - indicative of the high levels of swirl promoting fast combustion. This faster combustion, would be expected to be at a hotter temperature, and lead to higher ISNO emissions, which is the case with the SF closed case, but the reduction in effective $\mathrm{CR}$ caused by the $60 \mathrm{CAD}$ offset cam increases 
ignition delay and reduces in-cylinder pressures leading to a decrease in combustion temperatures and hence ISNO . The 60 CAD offset cam also has the fastest overall burn rate, with the baseline case having the slowest, and the SF90, closed and 30 CAD offset cam cases lying in the middle.

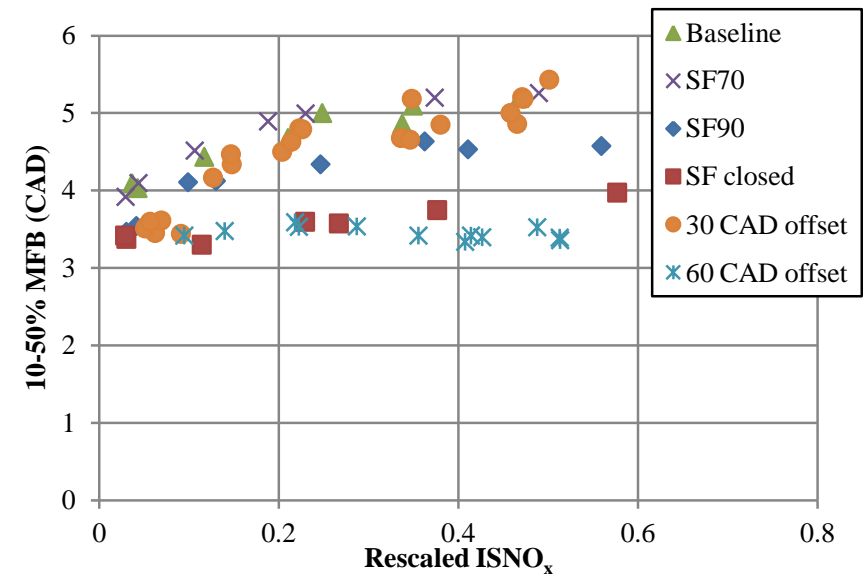

Figure 15: 10-50 MFB \% durations at 1500/3.5. The SF closed and 60 CAD offset cam can be seen to have the fastest initial burn.

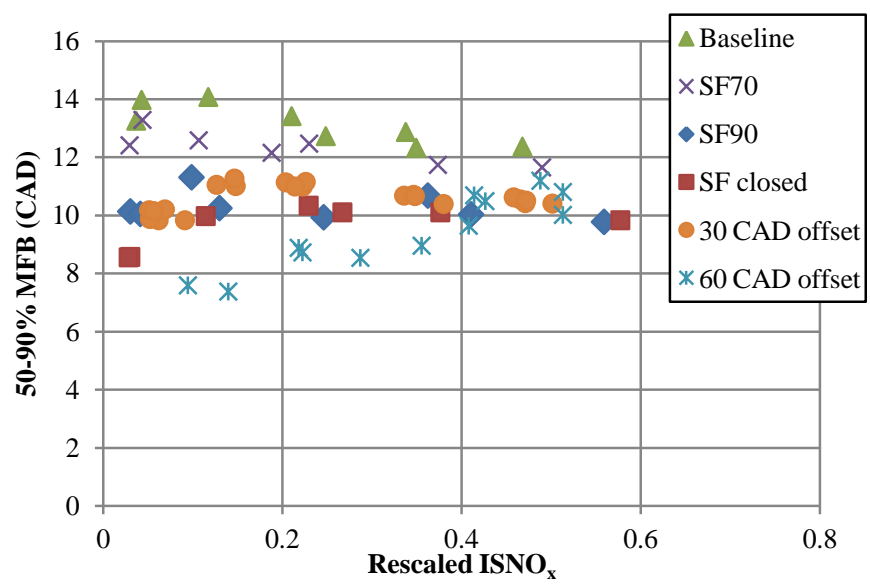

Figure 16: 50-90 \% MFB durations at 1500/3.5. The baseline case can be seen to have the slowest later burn, and the $60 \mathrm{CAD}$ offset cam the fastest.

Figure 17 shows the EGR rates needed for a given $\mathrm{ISNO}_{\mathrm{x}}$ emission at 1500/3.5. The highest levels of EGR are possible with the swirl flap cases, with a reduction in maximum EGR levels of $10 \%$ and $20 \%$ seen for the $30 \mathrm{CAD}$ and $60 \mathrm{CAD}$ offset cam cases respectively. The EGR levels could not be increased beyond these points in these cases due to a breakdown in combustion stability. This reduced EGR tolerance can be attributed to the reduction in effective compression ratio seen with these cams (Figure 3), leading to a lower overall oxygen availability in-cylinder, which when combined with the higher swirl levels convecting heat away from combustion is leading to unsustainable combustion. An increase in $\mathrm{ISNO}_{\mathrm{x}}$ for a given EGR level is observed for the SF90 and closed cases; this can be attributed to the faster, and therefore hotter, combustion for these cases (see Figure 16), the decrease in effective compression ratio seen with the offset cams "recovers" this increase due to lower in cylinder temperatures, without affecting the burn rate.

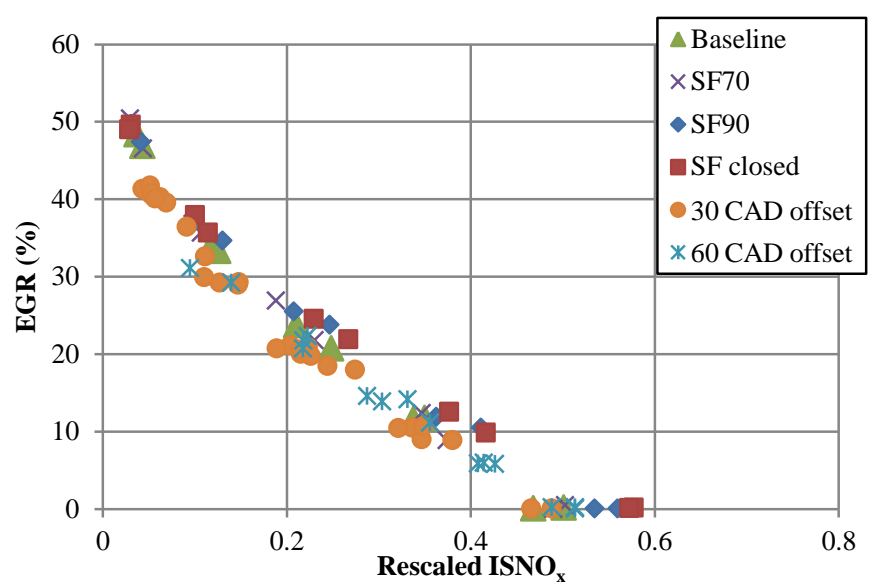

Figure 17: EGR levels achieved in each test at 1500/3.5. The effect of the reduced effective compression ratio with the offset cams in reducing ISNO for a given EGR rate can be seen.

\section{$1500 \mathrm{rpm} / 6.8$ bar nIMEP}

Figure 18 shows the FSN emissions at 1500/6.8. The Baseline case gives the highest FSN emission for a given $\mathrm{ISNO}_{\mathrm{x}}$ level. Closing the swirl flap has a benefit across the EGR range, reducing soot emissions for a given $\mathrm{ISNO}_{\mathrm{x}}$, with the exception of $0 \% \mathrm{EGR}$, where the soot levels are so low, that the effect of closing the SF is to increase $\mathrm{NO}_{\mathrm{x}}$ levels, with no effect on FSN. This increase in $\mathrm{ISNO}_{\mathrm{x}}$ at $0 \%$ EGR can be attributed to faster and therefore hotter combustion (see Figure 24). The $30 \mathrm{CAD}$ offset cam shows a small reduction in FSN levels, particularly at low levels of $\mathrm{ISNO}_{\mathrm{x}}$, without the $\mathrm{NO}_{\mathrm{x}}$ penalty at $0 \%$ EGR seen with the SF90 cases. The $60 \mathrm{CAD}$ offset cam again shows the engine entering an LTC regime with a flat $\mathrm{NO}_{\mathrm{x}}$-soot tradeoff, and the lowest $\mathrm{ISNO}_{\mathrm{x}}$ levels at $0 \%$ EGR. The dual benefits of decreased effective compression ratio (reducing $\mathrm{NO}_{\mathrm{x}}$ ), and increased swirl (reducing soot) are clearly seen here offering an opportunity for very low soot combustion at low $\mathrm{NO}_{\mathrm{x}}$ levels at the higher load condition as well.

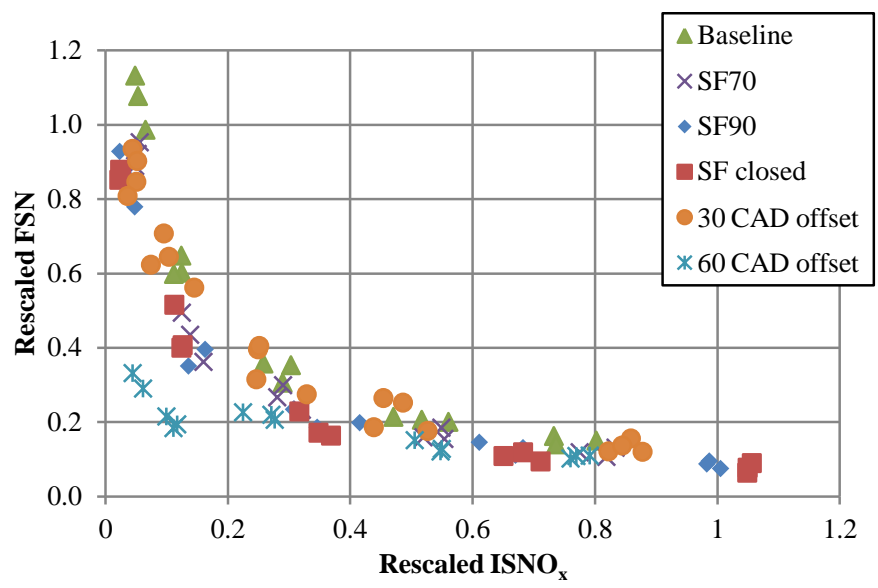

Figure 18: $\mathrm{ISNO}_{\mathrm{x}}-\mathrm{FSN}$ tradeoff at 1500/6.8. As at the lowest load point, the 60 CAD offset cam emits the lowest levels of FSN across the EGR range.

Figure 19 shows the ISTHC emissions at 1500/6.8. Across the SF sweep, low levels of THC emission are observed, with the SF 
position having no significant effect. Again, as at 1500/3.5 the increased swirl combined with reduced effective CR appears to be leading to incomplete combustion with the offset cams, giving significantly higher ISTHC emissions with both offset cams than for the Baseline and SF cases.

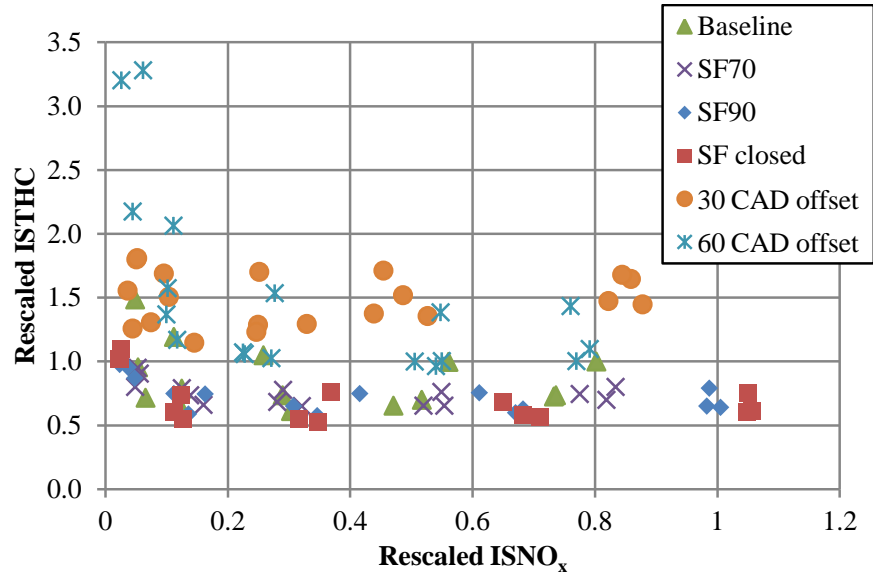

Figure 19: ISTHC emissions at 1500/6.8. Closing the SF has little effect on ISTHC emissions, however the offset cams lead to an increase in ISTHC emissions.

Figure 20 and Figure 21 show the ISCO emissions at 1500/6.8, both contain the same data points, Figure 20 shows the detail at the lower levels of EGR and Figure 21 the highest levels. At this load condition closing the SF lowers ISCO emissions across the EGR range due to better air/fuel mixing in-cylinder whereas both of the offset cams give ISCO emissions at similar levels to the baseline case. However at the highest levels of EGR (below 0.2 ISNO where oxygen availability is more limited these trends reverse - the SF closed emits higher levels of ISCO, and the 60 CAD offset cam gives very high levels of ISCO, most likely because at higher levels of swirl and reduced oxygen availability (and combustion temperature) the swirl is convecting the remaining heat away from the combustion process leading to incomplete combustion and high levels of ISCO emitted.

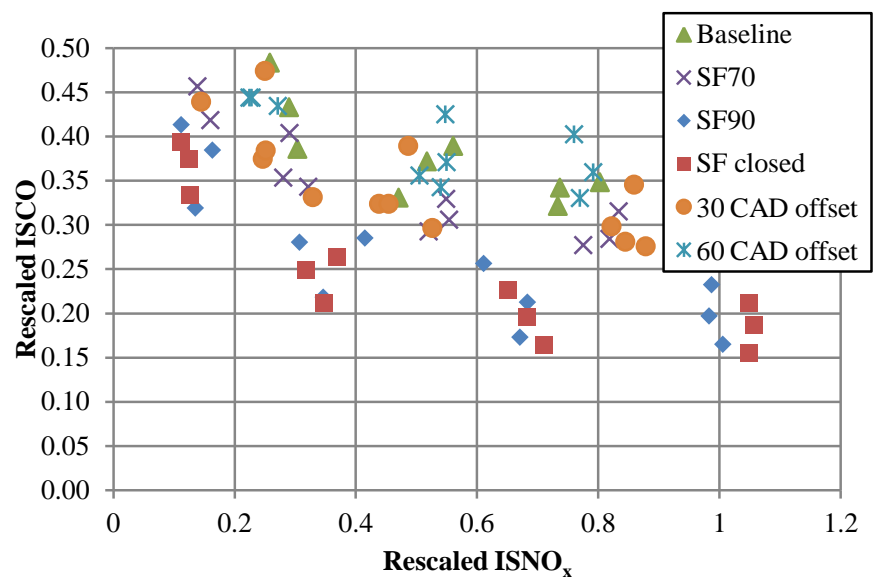

Figure 20: ISCO emissions at 1500/6.8. The lowest emissions are found with the SF closed, the offset cams give similar emissions to the baseline.

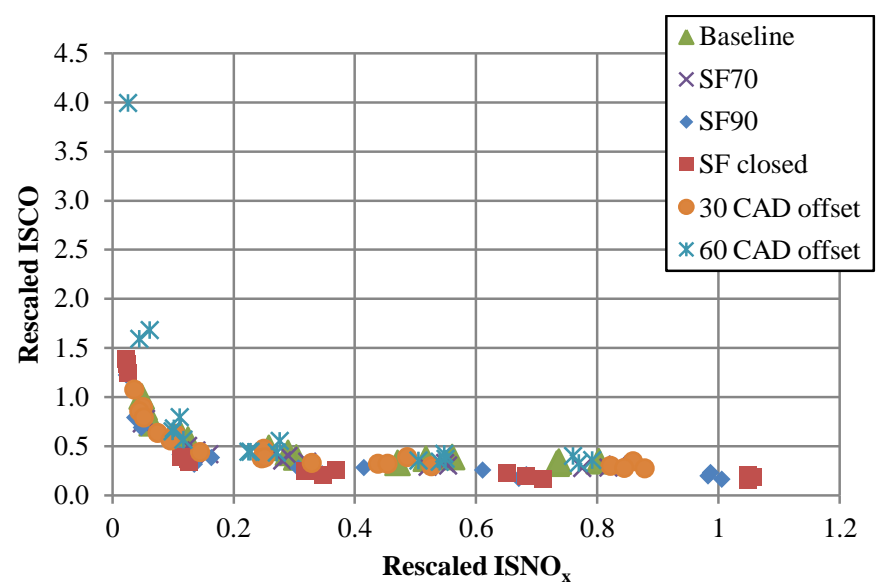

Figure 21: a rescaled Figure 20 showing the ISCO emissions at 1500/6.8 at the highest EGR levels (lowest ISNO levels). The $60 \mathrm{CAD}$ offset cam can be seen to have very high ISCO emissions here.

Figure 22 shows the ISFC at 1500/6.8. At this increased load condition the effect of the increased PMEP from the swirl flap is proportionally decreased (relative to engine load) and so the effect on ISFC is minimal. The SF sweep shows no significant differences with SF position; the same is true for the $30 \mathrm{CAD}$ offset cam. A small $-2-3 \%$ increase is observed with the 60 CAD cam - which can be attributed to similar reasons to those at the lower load condition, namely difficulty sustaining combustion at the high levels of swirl with reduced oxygen availability - note the increase is particularly acute at the highest levels of EGR - where combustion is just being sustained.

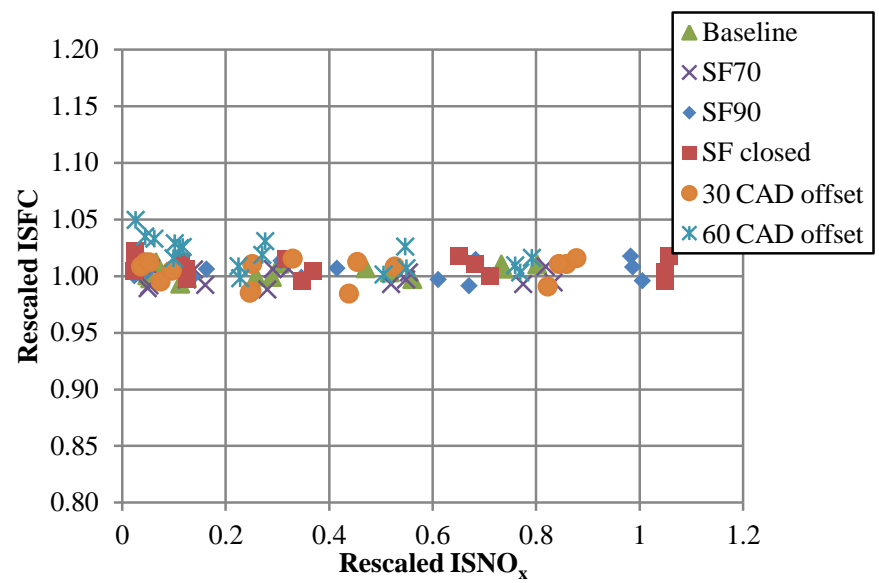

Figure 22: ISFC results at 1500/6.8. The SF sweep and 30 CAD offset cams give equivalent ISFC at this speed/load condition, the $60 \mathrm{CAD}$ offset cam leads to a small increase in ISFC, particularly at high levels of EGR.

Figure 23 shows the ignition delay at 1500/6.8. The trends seen at $1500 / 3.5$ (Figure 14) are repeated here, with the baseline case having the shortest ignition delay, and the $60 \mathrm{CAD}$ offset cam the longest. 


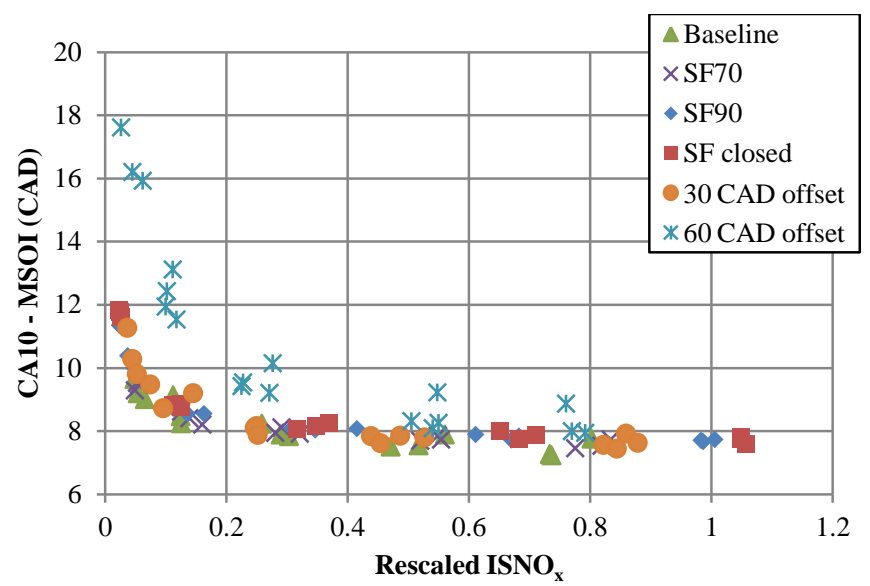

Figure 23: Ignition delay at 1500/6.8. The trends seen at 1500/3.5 are clearly seen here too, with a significantly increased ignition delay with the $60 \mathrm{CAD}$ offset cam.

Figure 24 shows the 10-90\% MFB duration at 1500/6.8. The effect of closing the SF can again clearly be seen - with the increased swirl leading to a faster, hotter combustion with increased levels of ISNO The 60 CAD offset cam's burn rate is insensitive to EGR, possibly as a result of reduced temperatures and pressures as well as already decreased oxygen availability with this cam.

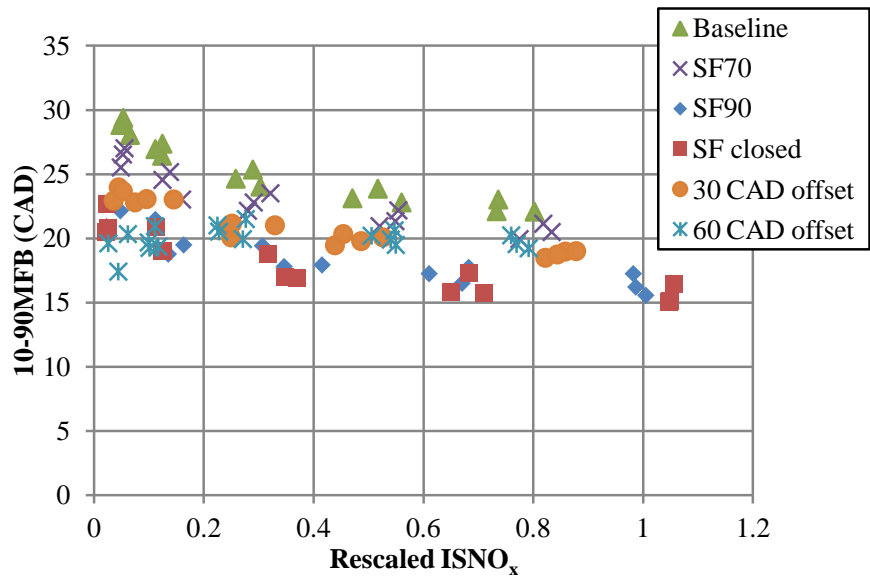

Figure 24: 10-90 \% MFB durations at 1500/6.8. The baseline case has the slowest burn rate, and the SF closed case the fastest.

Figure 25 shows the ISNO ${ }_{x}$ at each level of EGR tested. The effect of the swirl flap and offset cams can clearly be seen here: the swirl flap is mixing the fuel and air leading better leading to faster, hotter combustion and more ISNO $_{x}$ at a given EGR rate. The offset cam, reducing the effective compression ratio, reduces this increase, and in the case of the 60 CAD offset cam leads to a reduction in $\mathrm{ISNO}_{\mathrm{x}}$ relative to the baseline.

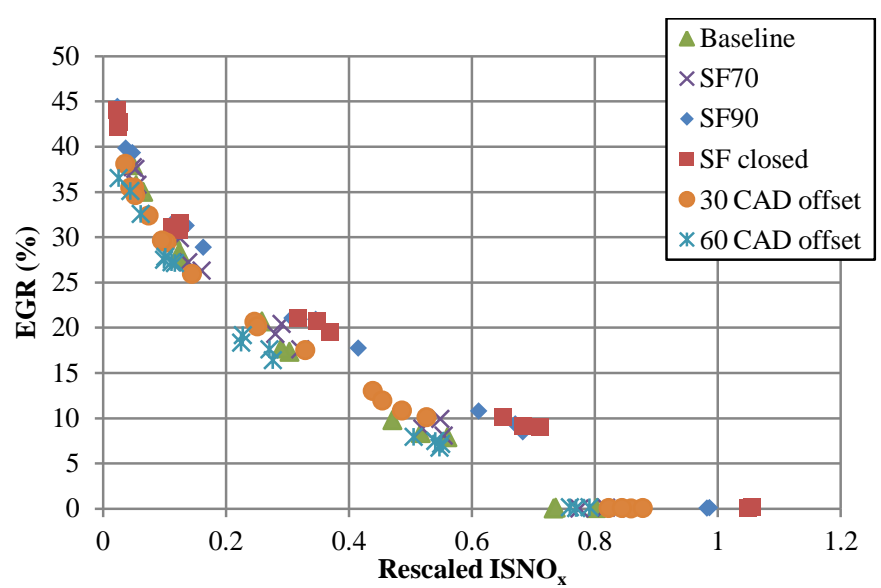

Figure 25: EGR levels achieved in each test at 1500/6.8. The effect of closing the swirl flap can be seen to increase the ISNO for a given EGR rate, the offset cams, on the other hand, reduce the $\mathrm{ISNO}_{\mathrm{x}}$ levels at a given EGR rate.

\section{$1750 \mathrm{rpm} / 13.5$ bar nIMEP}

Figure 26 shows the $\mathrm{NO}_{\mathrm{x}}$-Soot tradeoff at 1750/13.5. Here the trends observed at the previous two test points appear to be reversed; the baseline condition gives the least FSN for a given $\mathrm{ISNO}_{\mathrm{x}}$ value. The SF90 and 30 CAD offset cam give similar results with slightly higher FSN levels from the $30 \mathrm{CAD}$ offset cam. The SF closed and then $60 \mathrm{CAD}$ offset cam give the highest overall levels of FSN. It is of note that, in practice, swirl flaps are not used at these (relatively) high load points, and it is clear from these results why that is the case. With the high swirl, at high load, it is likely that heat is being convected away from the combustion process while fuel is still burning - resulting in incomplete combustion and higher FSN levels.

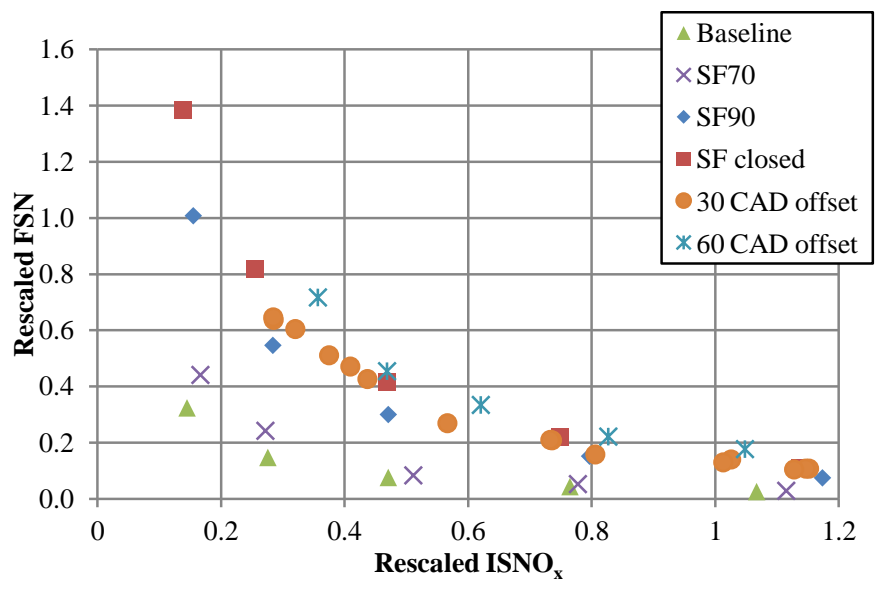

Figure 26: ISNO $_{x}-$ FSN tradeoff at 1750/13.5. The baseline case emits the lowest FSN for a given $\mathrm{ISNO}_{x}$, with both closing the SF and the offset cams both increase the FSN emissions at this speed/load condition.

Figure 27 shows the ISTHC emissions at 1750/13.5. Closing the SF can be seen to reduce the ISTHC emissions across the EGR range, in line with its effect at the other speed/load conditions. However, the offset cams do not have this effect, with the $60 \mathrm{CAD}$ offset cam having no significant effect compared to the baseline, and the 
30 CAD offset cam leading to an increase in ISTHC emissions across the EGR range.

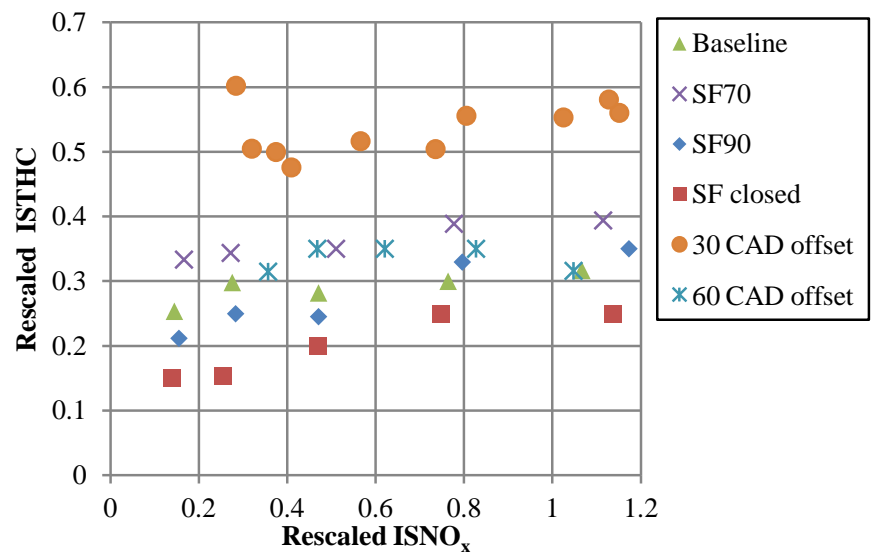

Figure 27: ISTHC emissions at 1750/13.5. Closing the swirl flap reduces the ISTHC emissions at this speed load condition, but the 30 CAD offset cam increases them.

Figure 28 shows the ISCO emissions at 1750/13.5. The baseline case (SF open) gives the lowest ISCO emissions across the EGR range, the SF closed case and offset cams emit the highest levels of ISCO. At the highest levels of EGR, which were not achievable with the offset cams (see Figure 32) the ISCO emissions are at their highest with the SF90 then SF closed cases, suggesting that the highest levels of swirl are convecting heat away from the combustion processes leading to incomplete combustion and high levels of ISCO at reduced oxygen availability (high EGR).

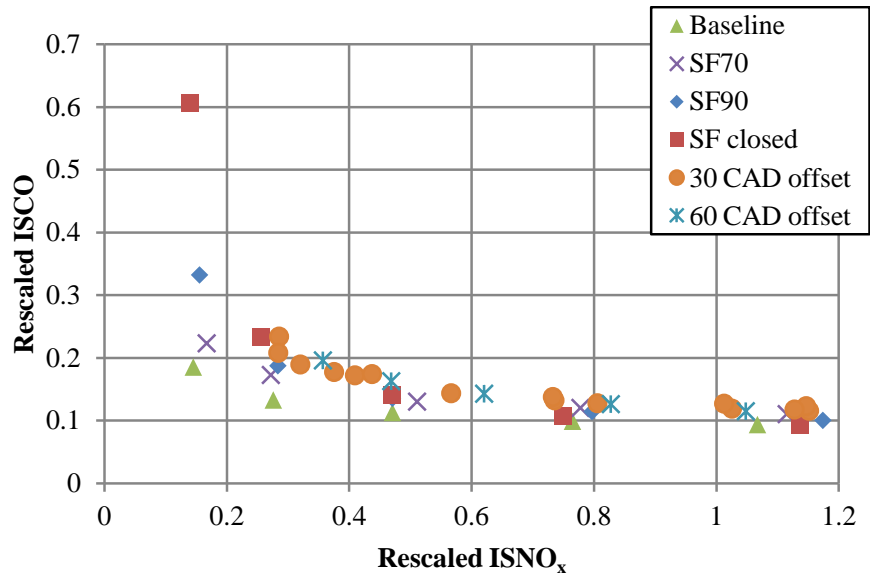

Figure 28: ISCO emissions at 1750/13.5. The baseline case (SF open) gives the lowest ISCO emissions across the EGR range, the SF closed case and offset cams emit the highest levels of ISCO.

Figure 29 shows the ISFC at 1750/13.5. The effect of closing the swirl flap on ISFC is seen most clearly at this point with the SF closure leading to an increase in pumping work (Figure 8), which gives an increase of up to $7 \%$ at this load/speed condition. Both of the offset cams give ISFC approximately equal to that of the SF closed condition at this load/speed condition.

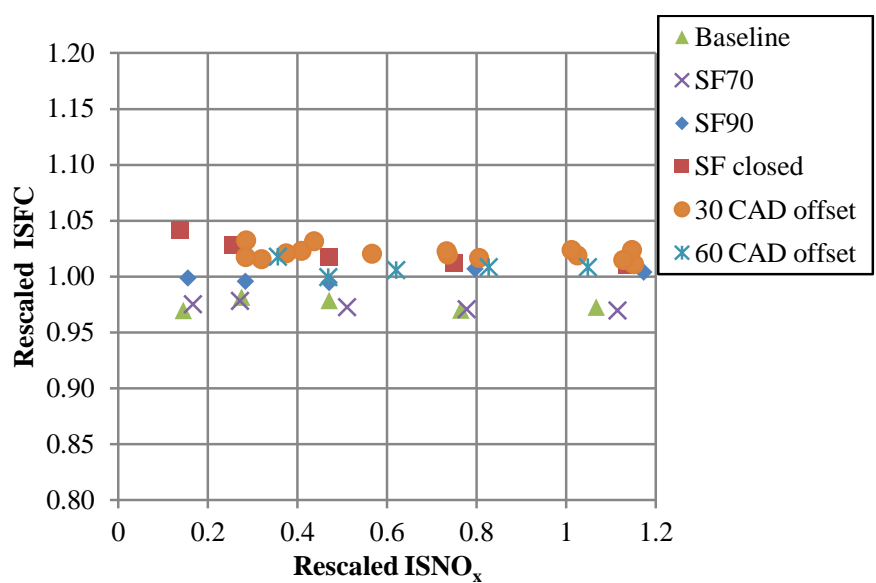

Figure 29: ISFC results at 1750/13.5. The offset cams, and closing the SF give a small increase in ISFC relative to the baseline.

Figure 30 shows the ignition delay at $1750 / 13.5$. The trends seen at the other two operating points are reversed here, with the SF closed at $60 \mathrm{CAD}$ offset cams having the shortest ignition delay and the baseline case having the longest delay. However, it should be noted that the differences in ignition delay are very small (a spread of around 0.5 CAD across the whole range) compared to the other test points. It is likely that the faster engine speed and additional load are masking the effects seen at the lower speed/load operating conditions. Adding EGR still increased ignition delay, in line with the other test points and the literature.

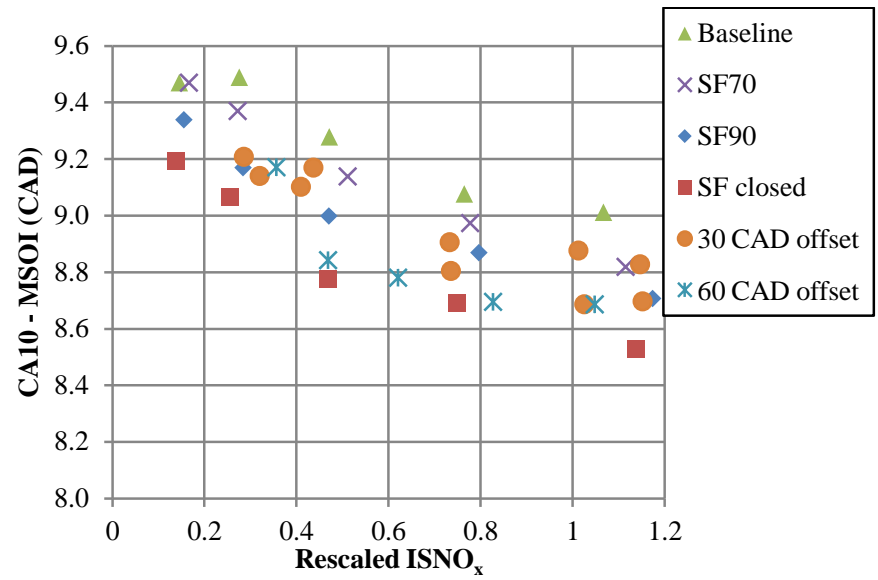

Figure 30: Ignition delay at 1750/13.5. Very small differences in ignition delay are noted with the SF sweep and offset cams.

Figure 31 shows the 10-90\% MFB duration at 1750/13.5. Here the trends seen in burn rate at 1500/3.5 and 1500/6.8 are reversed. The baseline case has the fastest burn rate, and the SF closed case the slowest. Here it is likely that the very high swirl rates, caused by the SF closure at high engine speeds, are convecting heat away from the combustion process. This is resulting in longer combustion durations, and (from the emissions results) incomplete combustion. The reduced oxygen availability and lower in cylinder temperatures and pressures from the offset cams appear to weaken this effect, but a more detailed understanding of the in cylinder processes would be needed to fully explain what was causing this. 


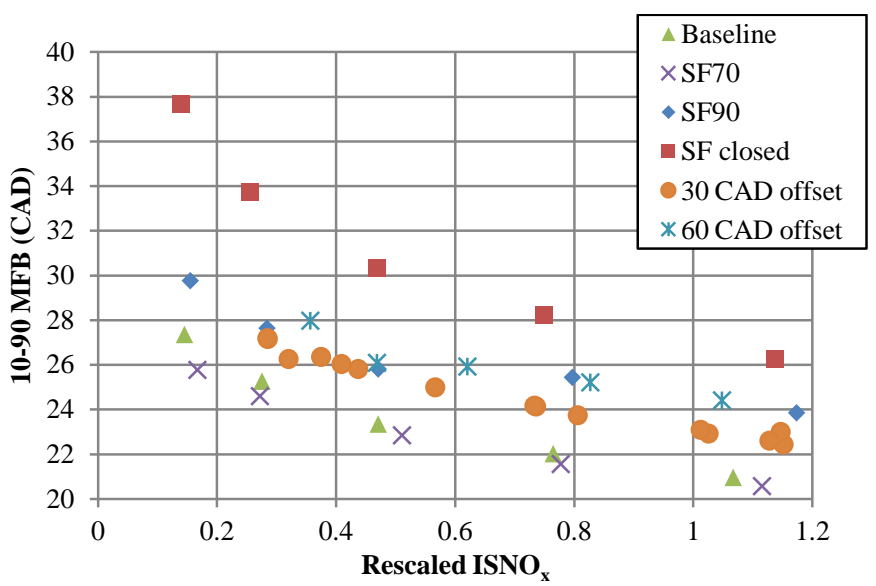

Figure 31: 10-90 MFB \% durations at 1750/13.5. The trends seen at the other operating points tested are reversed with the baseline case having the fastest burn, and the SF closed case the slowest.

Figure 32 shows the ISNO ${ }_{x}$ emissions at the EGR levels tested. Again it can be seen that the offset cams have a lower maximum EGR level than the SF cases - a reduction of over $10 \%$ for the $60 \mathrm{CAD}$ offset cam. In addition the effect of the reduced effective $\mathrm{CR}$ with the offset cams on $\mathrm{ISNO}_{\mathrm{x}}$ emissions can most clearly be seen here; both the $30 \mathrm{CAD}$ and particularly $60 \mathrm{CAD}$ offset cams give a $3 \%$ and $8 \%$ (respectively) reduction in $\mathrm{ISNO}_{\mathrm{x}}$ at higher levels of EGR, but a reduction is visible across the EGR sweep.

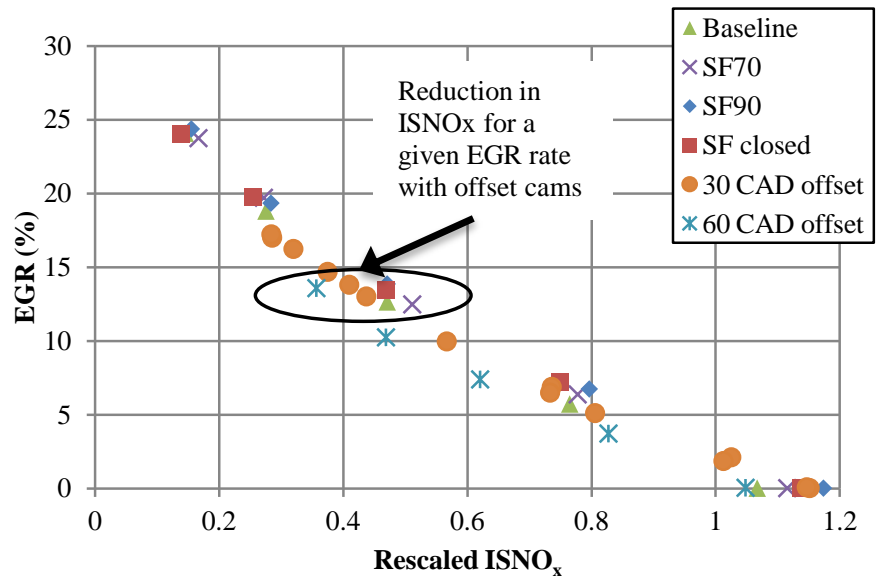

Figure 32: EGR levels achieved in each test at 1750/13.5. There are clear increases in $\mathrm{NO}_{\mathrm{x}}$ closing the $\mathrm{SF}$ and decreases in $\mathrm{NO}_{\mathrm{x}}$ with the offset cams, for a fixed EGR level.

\section{Summary/Conclusions}

A high speed diesel engine has been run with four different swirl flap settings, and two cams retarding the inlet swirl valve timing with varying levels of EGR at three operating conditions. The engine has been run with a fixed compression ratio and fixed base swirl (i.e. swirl generated from engine geometry). The retarded inlet swirl valve timing gives swirl levels in cylinder comparable to the operation of the swirl flap. The effect of retarding the inlet swirl valve timing is also to reduce the effective compression of the engine.
This reduces in cylinder temperatures and pressure as well as oxygen availability.

At 1500/3.5 the 60 CAD offset cam gives near zero smoke emissions at low levels of $\mathrm{NO}_{\mathrm{x}}$. However this reduction in soot comes at a penalty in ISFC, CO and THC emissions. These penalties are due to the high swirl convecting heat away from the reaction zone before combustion has had time to complete, combined with reduced oxygen availability (because of the reduced effective CR). Closing the SF can achieve smaller, but still significant, reductions in soot due to the engine entering a low temperature combustion regime. However the pressure drop this induces in the inlet, as well as the associated increase in pumping work leads to a higher ISFC than the baseline at this speed/load condition. The reduced effective CR and high swirl lead to a significant increase in ignition delay with the 60 CAD offset cam, but a significantly decreased combustion duration.

At $1500 / 6.8$ the 60 CAD offset cam is the only engine configuration tested to give very low smoke emissions at low levels of $\mathrm{NO}_{\mathrm{x}}$. At this operating point the THC and CO penalty is much less significant over the majority of the EGR range - as is the ISFC penalty (perhaps $1-2 \%$ over the majority of the EGR range). Here operating the SF only achieves minor reductions in soot and $\mathrm{CO}$, with no noted effect on ISFC. This operating point appears to be the "sweet spot" for the 60 CAD offset cam.

At the highest speed/load point tested (1750/13.5) the effect of both the SF and the offset cams was to increase ISFC relative to the baseline. At this point, the trends in $\mathrm{ISNO}_{\mathrm{x}}$ emissions witnessed at all operating conditions tested were most clearly seen where, for a given level of EGR, the operation of the SF increases the $\mathrm{NO}_{\mathrm{x}}$ emissions, due to the better mixing of fuel and air leading to faster hotter combustion and hence the higher $\mathrm{NO}_{\mathrm{x}}$ emissions. The offset cams, in decreasing the effective compression ratio, decrease the in cylinder temperatures and pressures, leading to lower $\mathrm{NO}_{\mathrm{x}}$ emissions. The $60 \mathrm{CAD}$ offset cam led to an $8 \%$ reduction in $\mathrm{ISNO}_{\mathrm{x}}$ emissions relative to the baseline at the highest levels of EGR. The emissions trends in both the operation of the swirl flap and the offset cams were reversed at this operating point compared to the two lower speed/load points tested. The SF and offset cams increased the FSN, CO, and THC emissions relative to the baseline; this demonstrates that as SFs are unlikely to be used at this condition (their use being confined to low speed/load conditions in current production engines), there is also no benefit to be had from using the offset cams at this point unless the focus is purely on $\mathrm{NO}_{\mathrm{x}}$ emissions, in which case their use still leads to a significant decrease in $\mathrm{ISNO}_{\mathrm{x}}$ at a given level of EGR.

At all operating points the use of the offset cams led to a reduction in EGR tolerance before combustion stability was lost - this is due to the reduced oxygen availability from the reduction in effective compression ratio caused by one inlet valve closing late. However the reduction in in cylinder temperatures and pressures meant that at 1500/6.8 the lowest levels of $\mathrm{NO}_{\mathrm{x}}$ were still achievable.

In this study we have seen that retarding valve opening can provide benefits to emissions, particularly soot at light load. The reductions in $\mathrm{NO}_{\mathrm{x}}$ emissions at all load conditions are a significant benefit. However, at most operating conditions the phased cam operation was not found to provide an improvement in performance across the whole spectrum of emissions when compared with the use of an optimised swirl flap calibration. With the combustion system tested, valve retard showed comparable results to an optimised swirl flap strategy. Such a strategy may have more opportunity with higher compression ratio combustion system design and different port 
characteristics, and when combined with variable valve actuation (as is found on engines in the market) would become an important optimisation parameter for engine calibrators.

\section{References}

1. SMMT, "New Car $\mathrm{CO}_{2}$ Report 2016".

2. Stone, R., "Introduction to internal combustion engines, $4^{\text {th }}$ ed." (Palgrave Macmillan, 2012). ISBN: 9780230576636.

3. Bosch, "Automotive Handbook. $8^{\text {th }}$ ed." (Robert Bosch GmbH, 2011). ISBN: 0837616867.

4. Zuelch, S., Behnk, K., Deepe, R., Findeisen, B. et al., "A New Hardware-Assisted Inlet Port Development Process for Diesel Engines Using Doppler Global Velocimetry," SAE Technical Paper 2005-01-0640, 2005, doi:10.4271/2005-01-0640.

5. Herzog, P. "HSDI diesel engine development towards Euro IV." in Future Engine and System Technologies The Euro IV challenge, IMechE Seminar Publication pp21-32. 1998.

6. Bach, M., et al., "Audi 4.0 V8 TDI". MTZ worldwide, 2003. 64(9): p. 2-5.

7. Mattes, W., et al., "The BMW six-cylinder diesel engine with Euro 4 technology". MTZ worldwide, 2004. 65(7): p. 7-11.

8. Bosch, "Diesel-Engine Management. 5th ed". (WileyBlackwell, 2005). ISBN: 0470026898.

9. Lancefield, T., "The Influence of Variable Valve Actuation on the Part Load Fuel Economy of a Modern Light-Duty Diesel Engine," SAE Technical Paper 2003-01-0028, 2003, doi:10.4271/2003-01-0028.

10. Ogawa, H., Li, T., Miyamoto, N., Kido, S. et al., "Dependence of Ultra-High EGR and Low Temperature Diesel Combustion on Fuel Injection Conditions and Compression Ratio," SAE Technical Paper 2006-01-3386, 2006, doi:10.4271/2006-01-3386.

11. Gurney, D., Mitcalf, J., Warth, M., Schneider, S. et al., "Integrated Simulation, Analysis and Testing of a Variable Valve Train for Passenger Car Diesel Engines," SAE Technical Paper 2012-01-0829, 2012, doi:10.4271/201201-0829.

12. Johnson, S., "Diesel Efficiency and Associated Fuel Effects", in CRC Workshop - Advanced Fuel \& Engine Efficiency Workshop. 2014: Baltimore, MD, USA.

13. Chittick, S., Swindell, M., and Raorane, S., "Analytical and Developmental Techniques Utilized in the Structural Optimization of a New Lightweight Diesel Engine," SAE Int. J. Engines 8(4):1960-1966, 2015, doi:10.4271/201501-2298.

14. Leach, F., Ismail, R., Davy, M., Weall, A. et al., "Comparing the Effect of Fuel/Air Interactions in a Modern High-Speed Light-Duty Diesel Engine”. SAE Technical Paper 2017-24-0075, 2017, doi:10.4271/2017-24-0075.

15. Ricardo, "Steady state flowbench port performance measurement and analysis techniques". Report DP93/0704, 1993.

16. Schneider, F. and Lettmann, M. "MAHLE CamInCam, die neue Lösung für variable Ventilsteuerzeiten. 16". in Aachener Kolloquium Fahrzeug-und Motorentechnik, 2007.

17. Auriemma, M., Caputo, G., Corcione, F., Valentino, G. et al., "Fluid-Dynamic Analysis of the Intake System for a HDDI Diesel Engine by STAR-CD Code and LDA Technique," SAE Technical Paper 2003-01-0002, 2003, doi:10.4271/2003-01-0002.
18. British Standards, "BS EN 590 Diesel, Requirements and Test Methods", 2009.

19. Akihama, K., Takatori, Y., Inagaki, K., Sasaki, S. et al., "Mechanism of the Smokeless Rich Diesel Combustion by Reducing Temperature," SAE Technical Paper 2001-010655, 2001, doi:10.4271/2001-01-0655.

20. Opat, R., Ra, Y., Gonzalez D., M., Krieger, R. et al., "Investigation of Mixing and Temperature Effects on HC/CO Emissions for Highly Dilute Low Temperature Combustion in a Light Duty Diesel Engine," SAE Technical Paper 2007-01-0193, 2007, doi:10.4271/200701-0193.

21. Wang, P and Hou, S. "Performance analysis and comparison of an Atkinson cycle coupled to variable temperature heat reservoirs under maximum power and maximum power density conditions". Energy Convers Manage, 46 (15-16) (2005), pp. 2637-2655.

22. Ladommatos, N., Abdelhalim, S., Zhao, H., and Hu., Z., "Effects of EGR on Heat Release in Diesel Combustion," SAE Technical Paper 980184, 1998, doi:10.4271/980184.

\section{Contact Information}

Felix Leach,

Dept of Engineering Science

University of Oxford

Parks Rd

Oxford

OX1 3PJ

UK

felix.leach@eng.ox.ac.uk

\section{Acknowledgments}

The authors would like to thank Jaguar Land Rover Limited and University of Oxford John Fell fund for financial support. The authors would also like to thank BP International for supplying the diesel fuel. The authors would like to thank Liyah Dholiwar for undertaking much of the engine testing and the Department of Engineering Science technicians and maintenance teams for facilities support. The authors would like to thank Sridhar Ayyapureddi, Paul Dunkley, and Zoe Versey of Jaguar Land Rover for the CFD simulation results.

\section{Definitions/Abbreviations}

BSFC

Brake specific fuel consumption

CA b(a)TDC

Crank Angle before (after) Top Dead Centre

CA10 Angle of $10 \%$ mass fraction burned

Page 12 of 13 


\begin{tabular}{|c|c|c|c|}
\hline CA50 & $\begin{array}{l}\text { Angle of } 50 \% \text { mass fraction } \\
\text { burned }\end{array}$ & JLR & Jaguar Land Rover \\
\hline \multirow[b]{2}{*}{ CA90 } & & LIVC & Late Inlet Valve Closure \\
\hline & $\begin{array}{l}\text { Angle of } 90 \% \text { mass fraction } \\
\text { burned }\end{array}$ & LTC & Low Temperature Combustion \\
\hline CAD & Crank Angle Degrees & MFB & Mass Fraction Burned \\
\hline $\mathrm{CO}$ & Carbon Monoxide & MSOI & $\begin{array}{l}\text { Main (injection) start of } \\
\text { injection }\end{array}$ \\
\hline CR & Compression ratio & & \\
\hline EGR & Exhaust Gas Recirculation & nIMEP & $\begin{array}{l}\text { Net Indicated Mean Effective } \\
\text { Pressure }\end{array}$ \\
\hline FSN & Filter Smoke Number & $\mathbf{N O}_{\mathbf{x}}$ & Nitrogen oxides \\
\hline IMEP & $\begin{array}{l}\text { Indicated Mean Effective } \\
\text { Pressure }\end{array}$ & PMEP & $\begin{array}{l}\text { Pumping mean effective } \\
\text { pressure }\end{array}$ \\
\hline ISCO & $\begin{array}{l}\text { Indicated Specific Carbon } \\
\text { Monoxide }\end{array}$ & SF & Swirl Flap \\
\hline \multirow[t]{2}{*}{ ISFC } & Indicated Specific Fuel & TDC & Top Dead Centre \\
\hline & Consumption & THC & Total HydroCarbons \\
\hline ISNOx & $\begin{array}{l}\text { Indicated Specific Oxides of } \\
\text { Nitrogen }\end{array}$ & & \\
\hline ISTHC & $\begin{array}{l}\text { Indicated Specific Total Hydro } \\
\text { Carbons }\end{array}$ & & \\
\hline
\end{tabular}

